\title{
Psychological Symptoms in Young Adults with Tension Type Headaches
}

\author{
Aysin Sinal \\ Department of Psychology \\ Girne American University \\ Cyprus \\ Turgay Akalın \\ Department of Health Sciences \\ Cyprus American University \\ Cyprus
}

\begin{abstract}
Our objective was to reveal the psychological symptoms of 18-25 y/o university students, who without a secondary disease complained of tension headaches in comparison to the psychological symptoms of the control group without headache and adult patients in the literature. To summarise, the mean test, where mean values of both sexes were taken together and the mean values of sparse and frequent episodic type headache groups were found to be higher than the control group. The Anova test used showed significant differences between the mean and frequency of headache-free and frequent episodic tension type headache. While the Pearson Correlation Analysis did not show any relationship between age and all psychological symptoms, there was a significant positive relationship between somatisation, depression and all psychological symptoms (except paranoia).
\end{abstract}

Foremost, our study results indicated the presence of psychiatric symptoms in tension-type headaches. These results determined similarities when compared to other related studies.

Keywords: Headache, Migraine, Tension Type Headache, SCL-90-R Psychological Symptom Research Scale, International Classification of Headache Disorders 3 (ICHD-3)

Tension Type Headaches (GTBA) are the most common headaches. Lifetime prevalence is 30-78\% (ICHD-3, https://ichd-3.org) GTBA has indeterminate symptoms. The pain is more bilateral, compressive and / or pressuresensitive and, unlike migraine, it is not throbbing. It does not increase with head movements or physical activities and does not accompany nausea and / or vomiting. The intensity of the pain is often mild or moderate.

The International Headache Society (IHS) published ICHD-3 in the classification of headache diseases in 2018. The new scientific evidence required changes to the previous classification, ICHD-3 beta (https: // ichd-3). The name, definition and location of some primary headaches defined for this purpose have been changed according to the International Classification of Headache Disorders 3 (ICHD-3) classification.

The GTBA ICHD-3 classifications, are divided into the following main headings:

1-Rare Episodic GTBA,

2-Frequent Episodic GTBA,

3-Chronic GTBA,

4- Potential GTBA

Tension Headache (GTBA), which occurs less than 15 days a month, is considered episodic, and Tension Headache that develops 15 or more times a month is considered chronic.

The SCL-90-R Psychological Symptom Screening Test, which was developed by Derogatis in 1977 and used in our study, had 90 items and 10 different symptom dimensions (somatisation, obsessive-compulsive symptoms, interpersonal sensitivity, depression, anxiety, anger-hostility, phobic anxiety, paranoid thinking, psychoticism and additional scales).

The SCL-90-R Psychological Symptom Screening Test provides a means of finding the mental symptom level of apparently normal individuals, assessing changes in mental symptom levels, assisting in predicted clinical procedures), and placing psychiatric patients into DSM III diagnostic groups. 


\section{Materials and Methods}

This study consisted of 75 tension type headache and 42 control cases without headache in the 18-25 age groups of Cyprus American University and Girne American University students.

A Headache questionnaire based on the ICHD-3 classification Tension Headache criteria, which was agreed as common language for Tension Headache, was given to those who complained of headache among the students and who wanted to voluntarily participate in the study.

Questionnaires asked whether the young person with headaches had a systemic disease, and those who reported systemic internal medicine, neurological and psychiatric diseases were not included in the study.

Those who did not answer all questions and those who gave inconsistent answers were excluded from the study.

Cases that met the criteria and gave a family history were interviewed.

The SCL-90-R test was performed to reveal the psychological symptoms in 75 GTBA cases that met the ICHD-3 criteria.

42 young control subjects who did not complain of headaches were also asked to fill out the BA questionnaire and SCL-90-R test was administered.

Psychological Symptoms of SCL-90-R Psychological Symptoms Screening Test consisting of 90 different sentences was given to participants. It was used to measure how uncomfortable the symptoms were in the past month. The degree of measurements is from zero to $4(0=$ none, 1 : very little, $2=$ Moderate, $3=$ Very high, $4=$ Extreme $)$. Thus, the psychological symptoms present in the students were graded themselves.

Responses were evaluated by the neurologist physician and specialist psychologist. 75 Tension Headache (47 rare episodic GTBAs, 27 frequent episodic GTBAs and one chronic GTBA) were determined.

\section{Results}

The study included 75 Tension Headaches (47 rare episodic GTBAs, 27 frequent episodic GTBAs and one chronic type GTBA). Chronic GTBA was not included in the study since it was only person.

In the study, the results obtained by SSL Statistical Method and SCL-90-R Psychological Symptom Search Test were evaluated with the following tests:

a) Mean and Standard Deviation of SCL-90-R subscales, headache diagnosis and control groups without headache, as male and female,

b) Correlation of SCL-90-R subscales (Pearson Correlation Matrix)

c) ANOVA test

\section{Summary of findings:}

1- In the mean test, the mean values of both sexes were taken together, and the mean values of the rare and frequent episodic type headache groups were found to be higher than the control group.

2- This was checked by Anova test. In the Anova Test, significant differences were found between the mean and frequency of headache-free and frequent episodic tension type headache (Somatisation $\mathrm{p}<.05$, others $\mathrm{p}<.01$ ). However, there was no such difference in depression $(\mathrm{p}=0.315)$.

3- Pearson Correlation Analysis did not show any relationship between age and all psychological symptoms. There was a significant positive relationship between somatisation and all psychological symptoms (other than paranoia) $(\mathrm{p}<.05)$. There was a significant positive relationship between depression and all other psychological symptoms ( $\mathrm{p}<.05)$.

Anxiety, obsession, interpersonal relationships, psychoticism, paranoia, anger, phobic, additional scale and all other psychological symptoms were significantly positive $(\mathrm{p}<.01)$.

\section{Debate}

Studies on primary headaches in adolescents and children have reported that headache is associated with anxiety and depression.

The main causes of tension headaches are anxiety, psychological stress, depression, somatisation disorder, muscle strain. In a study on tension-type headache patients, $90.2 \%$ had psychiatric co morbidity, of which $72.4 \%$ were diagnosed as anxiety and $56.1 \%$ were diagnosed as mood disorder (bipolar). Juang and colleagues reported $64 \%$ psychiatric co morbidity in Tension Headaches. 
Common sense has found somatoform pain disorder, depression and generalized anxiety disorder in Tension Headaches. Öyekçin and colleagues (2007) found the most common major depression in patients with primary headache.

In our study, the mean depression values of the Tension Headache subgroups were higher than the control group that did not complain of headaches. However, there was no such difference in depression in the Anova test $(\mathrm{p}=0.315)$. This may be attributed to the limited number of young university students.

In a study conducted by Puca and colleagues on tension headaches, anxiety was $52.5 \%$, depression $36.4 \%$, somatoform disorder $21.7 \%$.

$42.5 \%$ of the patients had a psychiatric disorder. These are $20 \%$ depression, $10 \%$ BAD, $5 \%$ depression and anxiety, $5 \%$ OCD, $2.5 \%$ acute stress reaction.

In our study, somatisation, anxiety, obsession, depression, interpersonal sensitivity, psychosis, paranoia, anger, phobic and additional scale symptom levels were found to be higher in tension-type headache cases compared to control group without headache. This supports the presence of psychiatric symptoms in young rare and frequent episodic tension headache patients in our study.

In the studies conducted by Kocabaş and Çelebi among boarding female students between 14 and 18 years of age, anxiety, depression and neurotic tendency levels were higher in migraine and tension headache groups compared to control group. Bille, Price and Ziegler's work in migraine and tension headaches, anxiety, depression and neurotic tendency levels were higher than control group. In our study, anxiety and depression levels were higher than the control group without headache $(\mathrm{p}<.01)$.

Most authors have reported that acute anxiety causes headache in migraine and tension headaches.

Tanrıverdi and Gözüm investigated the psychiatric symptom levels in GTBA cases. They found that somatisation, depression, interpersonal sensitivity, anger-hostility and anxiety were higher than the comparison group. In our study, somatisation, depression, interpersonal sensitivity, anger and anxiety were higher than the control group without headache $(\mathrm{p}<.01)$.

Depression and anxiety symptom levels were significantly higher in tension-type headaches by some researchers (Tanrıverdi-Gözüm.2009). In our study, depression and anxiety were significantly higher in tension-type headaches compared to control group without headache $(\mathrm{p}<.01)$. In our study, there were significant differences in all psychological symptoms except for depression in the investigation of the differences between tension type headache groups according to diagnostic groups.

\section{Result:}

1- Foremost, we found our study indicated the presence of psychiatric symptoms in tension-type headaches.

2- The mean values of the psychiatric symptoms present were higher in both diagnostic groups than in the control group (except depression).

3- This situation was compared with the results of similar studies in the literature and determined similarities

This study was conducted among a limited number of students among young university students. Our aim was to determine the presence of psychological symptoms in young migraine and tension headache students. It is noteworthy that these symptoms have significant similarities when compared with those of other age groups.

In order to make a generalised study, it is necessary to work with a larger sample. 
Table 1 Descriptive Statistics for the Sample of Students $(\mathbf{N}=117)$

Descriptive Statistics for the Sample of Students $(\mathrm{N}=117)$ SOM, anxiety $=$ ANK, obsession $=$ OC, depression $=$ DEP, interpersonal sensitivity $=$ INT, psychotic $=$ PSY, paranoia $=$ PAR, anger $=$ HOS, phobic $=$ FHOB, supplement $=$ ASI, GSIndex $=$ GSI

\begin{tabular}{|c|c|c|c|c|c|c|}
\hline \multirow[b]{3}{*}{ Diagnosis } & \multicolumn{4}{|l|}{ Gender } & \multirow{2}{*}{\multicolumn{2}{|c|}{ All }} \\
\hline & \multicolumn{2}{|c|}{ Male } & \multicolumn{2}{|c|}{ Female } & & \\
\hline & Mean & SD & Mean & SD & Mean & SD \\
\hline Control SOM & .797 & 1.51 & 1.10 & 2.19 & .889 & 1.72 \\
\hline SEG & - & - & 1.12 & .676 & 1.02 & .569 \\
\hline SEB & 1.27 & .727 & 1.34 & .929 & 1.32 & .859 \\
\hline KGB & - & - & - & - & - & - \\
\hline Control ANK & .524 & .434 & .423 & .297 & .492 & .396 \\
\hline SEG & 1.05 & .689 & 1.28 & .665 & 1.02 & .569 \\
\hline SEB & 1.40 & 1.22 & 1.28 & .901 & 1.33 & 1.01 \\
\hline KGB & - & - & - & - & - & - \\
\hline Control O-C & .978 & .604 & 1.00 & .348 & .985 & .534 \\
\hline SEG & 1.71 & .471 & 1.83 & .570 & 1.77 & .522 \\
\hline SEB & 1.91 & .660 & 2.05 & .682 & 2.00 & .665 \\
\hline KGB & - & - & - & - & - & - \\
\hline Control DEP & 1.57 & 2.23 & .739 & .528 & 1.32 & 1.91 \\
\hline SEG & 1.23 & .623 & 1.73 & .618 & 1.49 & .661 \\
\hline SEB & 1.42 & .710 & 1.92 & .800 & 1.74 & .794 \\
\hline KGB & - & - & - & - & - & - \\
\hline Control INT & .672 & .689 & .623 & .419 & .657 & .613 \\
\hline SEG & 1.35 & .584 & 1.66 & .504 & 1.51 & .560 \\
\hline SEB & 1.36 & .647 & 1.77 & .625 & 1.61 & .654 \\
\hline KGB & - & - & - & - & - & - \\
\hline Control PSY & .310 & .341 & .200 & .258 & .276 & .319 \\
\hline SEG & .878 & .545 & .958 & .583 & .919 & .560 \\
\hline SEB & .760 & .594 & 1.06 & .698 & .951 & .667 \\
\hline KGB & - & - & - & - & - & - \\
\hline Control PAR & .752 & .688 & .858 & .480 & .785 & .627 \\
\hline SEG & 1.55 & .664 & 1.63 & .711 & 1.60 & .682 \\
\hline SEB & 1.33 & .773 & 1.85 & .647 & 1.66 & .728 \\
\hline KGB & - & - & - & - & - & - \\
\hline Control HOS & .902 & .610 & .743 & .614 & .853 & .608 \\
\hline SEG & 1.52 & .923 & 1.52 & 1.14 & 1.52 & 1.03 \\
\hline SEB & 1.13 & 1.18 & 1.89 & .824 & 1.61 & 1.02 \\
\hline KGB & - & - & - & - & - & - \\
\hline Control PHOB & .181 & .292 & .241 & .205 & .200 & .267 \\
\hline SEG & .627 & .588 & .726 & .489 & .677 & .536 \\
\hline SEB & .614 & .591 & .940 & .848 & .819 & .767 \\
\hline KGB & - & - & - & - & - & - \\
\hline Control AS & .753 & .539 & .724 & .366 & .744 & .488 \\
\hline
\end{tabular}




\begin{tabular}{|l|ll|ll|ll|} 
SEG & 1.36 & .578 & 1.42 & .686 & 1.39 & .629 \\
SEB & 1.19 & .583 & 1.53 & .891 & 1.41 & .796 \\
KGB & - & - & - & - & - & - \\
\hline Control GSI & .635 & .434 & .593 & .275 & .622 & .389 \\
& & & & & & .425 \\
SEG & 1.20 & .439 & 1.39 & .397 & 1.30 & .663 \\
SEB & 1.26 & .671 & 1.56 & .652 & 1.45 & - \\
KGB & - & - & - & - & - &
\end{tabular}

Rare Episodic Tension Headache $=$ SEG, Frequent Episodic Tension Headache $=$ SEB , Chronic Tension Headache $=$ KGB Chronic GTBA was not included in the study because it was 1 person.

The control group consisted of students who did not define headache

Table 2Pearson Correlation Matrix among the variables

\begin{tabular}{|l|lllllllllll|}
\hline & SOM & $A N K$ & $O-C$ & $D E P$ & $I N T$ & $P S Y$ & $P A R$ & HOS & FHOB & ASI & GSI \\
\hline Age & .001 & -.057 & .020 & .011 & -.004 & .029 & -.007 & -.099 & -.003 & .036 & -.027 \\
SOM & & $.329^{*}$ & $.257^{* *}$ & $.354^{* *}$ & $.276^{* *}$ & $.258^{* *}$ & .129 & $.255^{* *}$ & $.333^{* *}$ & $.256^{* *}$ & $.357^{* *}$ \\
ANK & & & $.666^{* *}$ & $.435^{* *}$ & $.705^{* *}$ & $.768^{* *}$ & $.551^{* *}$ & $.628^{* *}$ & $.759^{* *}$ & $.650^{* *}$ & $.887^{* *}$ \\
O-C & & & & $.353^{* *}$ & $.718^{* *}$ & $.620^{* *}$ & $.585^{* *}$ & $.508^{* *}$ & $.614^{* *}$ & $.617^{* *}$ & $.826^{* *}$ \\
DEP & & & & & $.396^{* *}$ & $.416^{* *}$ & $.309^{* *}$ & $.345^{* *}$ & $.435^{* *}$ & $.323^{* *}$ & $.478^{* *}$ \\
INT & & & & & & $.762^{* *}$ & $.714^{* *}$ & $.549^{* *}$ & $.723^{* *}$ & $.604^{* *}$ & $.867^{* *}$ \\
PSY & & & & & & & $.628^{* *}$ & $.547^{* *}$ & $.726^{* *}$ & $.597^{* *}$ & $842^{* *}$ \\
PAR & & & & & & & & $.561^{* *}$ & $.570^{* *}$ & $.469^{* *}$ & $.721^{* *}$ \\
HOS & & & & & & & & &. $.542^{* *}$ & $.465^{* *}$ & $.702^{* *}$ \\
FHOB & & & & & & & & & & $.592^{* *}$ & $.821^{* *}$ \\
ASI & & & & & & & & & & & $.766^{* *}$ \\
GSI & & & & & & & & & & & \\
\hline
\end{tabular}

Somatization $=$ SOM, anxiety $=$ ANK, obsession $=\mathrm{O}-\mathrm{C}$, depression $=\mathrm{DEP}$, interpersonal sensitivity $=$ INT, psychotic $=\mathrm{PSY}$, paranoia $=\mathrm{PAR}$, anger $=$ HOS, phobic $=$ FHOB, attachment $=$ ASI, GS Index $=$ GSI

Table 3 Summary of ANOVA testing the difference in these symptoms

\begin{tabular}{|c|c|c|c|c|c|c|c|}
\hline & & $\begin{array}{l}\text { Sum of } \\
\text { Squares }\end{array}$ & $\mathrm{df}$ & $\begin{array}{l}\text { Mean } \\
\text { Square }\end{array}$ & $\mathrm{F}$ & Sig. & MEANING \\
\hline \multirow{3}{*}{ Somatization } & Between Groups & 16,419 & 5 & 3,284 & 2,610 & ,026 & $S$ \\
\hline & Within Groups & 234,054 & 186 & 1,258 & & & \\
\hline & Total & 250,473 & 191 & & & & \\
\hline \multirow{3}{*}{ Anxiety } & Between Groups & 25,652 & 5 & 5,130 & 11,742 & ,000 & S \\
\hline & Within Groups & 81,267 & 186 & ,437 & & & \\
\hline & Total & 106,919 & 191 & & & & \\
\hline \multirow{2}{*}{ Obsession } & Between Groups & 31,810 & 5 & 6,362 & 16,226 & ,000 & $S$ \\
\hline & Within Groups & 72,928 & 186 & ,392 & & & \\
\hline
\end{tabular}




\begin{tabular}{|c|c|c|c|c|c|c|c|}
\hline & Total & 104,738 & 191 & & & & \\
\hline \multirow{3}{*}{ Depression } & Between Groups & 7,147 & 5 & 1,429 & 1,191 &, 315 & NS \\
\hline & Within Groups & 223,184 & 186 & 1,200 & & & \\
\hline & Total & 230,332 & 191 & & & & \\
\hline \multirow{3}{*}{$\begin{array}{l}\text { Interpersonal } \\
\text { sensitivity }\end{array}$} & Between Groups & 34,303 & 5 & 6,861 & 14,153 & ,000 & $S$ \\
\hline & Within Groups & 90,165 & 186 & ,485 & & & \\
\hline & Total & 124,469 & 191 & & & & \\
\hline & Between Groups & 17,430 & 5 & 3,486 & 11,070 & ,000 & $S$ \\
\hline \multirow{3}{*}{ Psychotic } & Within Groups & 58,570 & 186 & ,315 & & & \\
\hline & Total & 76,000 & 191 & & & & \\
\hline & Between Groups & 22,591 & 5 & 4,518 & 8,863 & ,000 & $S$ \\
\hline \multirow{3}{*}{ Paranoia } & Within Groups & 94,820 & 186 & ,510 & & & \\
\hline & Total & 117,411 & 191 & & & & \\
\hline & Between Groups & 17,234 & 5 & 3,447 & 3,917 & ,002 & $S$ \\
\hline \multirow{3}{*}{ Anger } & Within Groups & 163,655 & 186 & ,880 & & & \\
\hline & Total & 180,889 & 191 & & & & \\
\hline & Between Groups & 16,894 & 5 & 3,379 & 10,280 &, 000 & $\mathrm{~S}$ \\
\hline \multirow{3}{*}{ Phobic } & Within Groups & 61,132 & 186 & ,329 & & & \\
\hline & Total & 78,026 & 191 & & & & \\
\hline & Between Groups & 22,897 & 5 & 4,579 & 10,676 & ,000 & $\mathrm{S}$ \\
\hline \multirow{2}{*}{ Attachment } & Within Groups & 79,783 & 186 &, 429 & & & \\
\hline & Total & 102,680 & 191 & & & & \\
\hline
\end{tabular}




\begin{tabular}{|ll|l|l|l|l|l|l|}
\hline GS Index & Between Groups & 25,037 & 5 & 5,007 & 18,744 &, 000 & $\mathrm{~S}$ \\
& Within Groups & 49,691 & 186 &, 267 & & & \\
Total & 74,729 & 191 & & & \\
\hline
\end{tabular}

\section{References}

Bille B: Migraine in school children.ActaPediatrScand 51(Suppl):136,1962

Dağ İ.:BelirtiTaramaListesi(SCL-90-R)'ninÜniversiteÖğrencileriiçinGüvenirliğiveGeçerliği.TürkPsikiyatrıDergisi 1991, 2(1): 5-12

GüleçM. Psikosomatikhastalıklarda mica vekarakter.PsikiyatrideGüncelYakla Wilkins,2004şımlar. 2009;1:201-14.

The International Classification of Headache Disorders 3rd edition (beta version) Cephalalgia,2013;33:629-808

The International Classification of Headache Disorders, 3rd edition Cephalalgia,2018;38:1-211

Juang KD, Wang SJ, Fuh JL, Lu SR, Su TP.Comorbidity of depressive and anxiety disorders in chronic daily headache and its subtypes. Headache. 2000;40:818-23.

KılıçM.:BelirtiTaramaTestiListesi(SCL-90-R'ninGeçerlilikveGüvenirliliği.PsikolojikDanışmaveRehberlik Dergisi,1991Cilt : 1, Say1 : 2:45-52.

Kocabaş Z.,Çelebi A.:MigrenveGerilimBaşağrısındaAnksiyete,DepresyonveNörotikeğilimDüzeyleri.Düşünen Adam;1997,10(3):17-2

MarcussenRM: Vascular headache experimentally induced by presentation of pertinent life experiences: Modification of course of vascular headache by alternation of situations and reactions. Ass Res NervMent Dis Proc 29:60914, 1949.

MerskyH: Psychiatric headache.In FC Rose (ed).Handbook of clinical neurology. ElseiverSci Pub 48:353-66,1986

MonginiF, Rota E, Deregibus A, Ferrero L, Migliaretti G, Cavallo F, Mongini T, Novello A. Accompanying symptoms and psychiatric comorbidity in migraine and tension-type headache patients. J Psychosom Res. 2006;61:44751.

Öyekçin D G, Sarıkaya O, Duraklı M, Erol A: Başağrısı tipi ilepsikiyatrikeştanı, depresyonveanksiyetedüzeyleriarasındakiilişkininincelenmesi. AnadoluPsikiyatri Dergisi.2007; 8:281-6

ÖzmenE, Demet MM, Gülseren L, Kültür S: Diagnosis of DSM-III-R in somatic patients with psychiatric outpatient clinic. Thinking Adam Derg 1-2: 16-21, 1993.

Powers SW,GilmanDK,Hershey Ad: Headache and psychological functioning in children and adolescents. Headache.2006;46: 1404-15

Price KP,Blackwell S: Trait levels of anxiety and psychological responses to stress in migraineus and normal controls. J.Clin.Psychol 3:658-60,1980.

Puca FM, Antonaci F, Genco S, Savarese M, Bussone G, D'Amico D et al. Psychiatric comorbidity and psychosocial stress in patients with tension-type headache from headache centers in Italy. The Italian Collaborative Group for the Study of Psychopathological Factors in Primary Headaches..Cephalalgia. 1999 Apr;19(3):159- 64.

SandriniG, VerriAP,Sicuteri F, Marabini S: Psychiatric comorbidity and psycosocial stress in patiens with tension-typr headache from headache centers in İtaly. The Italien Collaborative Group for the Study of Psychopathological Factors in Primary Headaches.Cephalalgia .199;19:159-64

SağduyuA:Somatizasyonunveilişkilisendromlarınbiyolojisi.TürkPsikiyatri Dergisi.2001;12:211-24

Sayılgan N, Domaç F. M., Güleç H: Migrenve Gerilim tipi başağrısıtanılıbireylerdepsikiyatrikeştanıveyaşamkalitesiileilişkisi:önçalışma.ÇukurovaMedikal Jurnal,2019,44(1):44-51

Sandrini G, Manzoni GC, Zanferrari C, Nappi G: An epidemiological approach to the nosography of chronic daily headache. Cephalalgia 13(Suppl 12):72-77, 1993.

Tanrdağverdi D., GözümS .: Tension Type Comparison of psychiatric symptoms in adults with and without headache. Journal of Ataturk University School of Nursing, 2009; 12: 4: 11-17 (Anatolian Journal of Nursing and Health Sciences. 2010; 12 (4): 18-11.)

Ziegler DK,Rhodes RJ, Hassein RS: Association of psychological measurement of anxiety and depression with headache history in a non clinicalpopulation. ResClin Study Headache 6:23-35,1978. 